\title{
Promoviendo el sentido del humor en las personas adultas con discapacidad intelectual y del desarrollo
}

\section{Promoting humour in adults with intellectual and developmental disabilities}

\section{Resumen}

Diferentes investigaciones demuestran la importancia del sentido del humor en el bienestar personal y la salud. En el presente trabajo se plantea examinar la utilidad e idoneidad para personas con discapacidad intelectual de la visualización y lectura de material humorístico en soporte impreso destinado a la población general, con un nivel de lectura característico de las edades comprendidas entre los I I y I 2 años; así como analizar si el modelo multidimensional del sentido del humor de García-Larrauri (2006) es aplicable a la población del presente estudio; y descubrir las preferencias de los participantes entre el material en soporte impreso: "sólo texto" o "texto con dibujos". Los resultados indican que las personas con discapacidad intelectual desarrollan experiencias de humor que pueden aprovecharse para aumentar su calidad de vida. Una buena forma de promoverlo es utilizando la literatura de humor popular, adaptada en forma de textos sencillos y/o acompañados de dibujos.

\section{Palabras clave}

Discapacidad intelectual, sentido del humor, literatura de humor, bienestar personal.

\begin{abstract}
Lately researchers have shown the importance of humour and its relation to personal well-being and health. The present work deals with the humour of people with intellectual and developmental. One of the objectives of the article is to examine to what extent the humorous reading material intended for a general population with an I I-I 2 year-old's reading level is appropriate and useful for persons with intellectual and developmental disabilities. The second purpose of the article is to analyze whether García-Larrauri's Multidimensional Sense of Humor Model (2006) can be applied to the present investigation's population and to reveal their preferences between two different reading materials: "only text" or "text with illustrations". The results indicate that people with intellectual disabilities develop experiences of humour that can be used to enhance their quality of life. A good way to promote this process is using the popular literature of humour adapting it into simple texts and / or accompanying it with drawings.
\end{abstract}

\section{Keywords}

Intellectual disability, sense of humour, humour literature, personal wellbeing.

\section{Daniel Paredes Gómez \\ ‘dapago@cop.es〉}

Centro Ocupacional Aprosuba-4. FEAPS Extremadura

\section{Antonio Flores Nieto 〈antflores@unex.es〉}

Universidad de Extremadura

Para citar:

Paredes Gómez, D. y Flores Nieto, A. (2OI4): "Promoviendo el sentido del humor en las personas adultas con discapacidad intelectual y del desarrollo", Revista Española de Discapacidad, 2 (2): 2I9-23I.

$<$ http://dx.doi.org/IO.5569/23405104.02.02.I2>

Fecha de recepción: 05-O2-20I4 Fecha de aceptación: 22-09-20I4 


\section{Discapacidad intelectual y experiencia emocional del sentido del humor}

Las emociones positivas son necesarias para las personas pues facilitan su adaptación social. Experimentarlas aportan considerables beneficios psicológicos y bienestar emocional. Por ejemplo, mejoran la fluidez del pensamiento, motivan a seguir adelante frente a los avatares negativos de la vida o facilitan las soluciones creativas a los problemas (Avia, I995, I998; Vecina, 2006).

El "sentido del humor" es considerado como una emoción positiva y ha sido descrito como un fenómeno que atañe a la capacidad humana para experimentar y estimular unas reacciones muy específicas; la sonrisa y la risa (observable o no), y de esta manera conseguir o mantener un estado de ánimo positivo (Carbelo y Jáuregui, 2006). Otros autores han constatado en sus estudios los beneficios del sentido del humor a nivel personal, como una mejora no sólo a nivel de bienestar psicológico sino también a nivel de la salud física (Kuiper et al., 2004). Estos resultados son tan consensuados en la comunidad científica que, como indican Moran y Hughes (2006), el empleo de actividades que generen humor es cada vez más aceptado como estrategia para hacer frente al estrés. Entre los argumentos en que se basan estos autores se puede determinar que la tendencia a usar el humor de forma social ayuda a las personas a obtener el apoyo social y a reducir estrés. Siendo el apoyo social engendrado por el humor incluso más importante que el propio humor en sí (Moran y Hughes, 2006).

Los beneficios que a nivel de salud pueden derivarse de la experimentación están en parte originados por la risa y los cambios fisiológicos que la acompañan, más concretamente a nivel muscular, cardiovascular, endocrino y neuronal (Martin, 2004). Esta reacción de risa que acompaña al sentido del humor relaja los músculos, mejorando la respiración, la función cardiovascular y sobre todo la función endocrina, tendente a reducir el estrés. Pero como indica Martin (2004), el humor puede además beneficiar la salud de forma indirecta, debido a que las personas que tienden a emplear el humor para reducir los conflictos interpersonales aumentan los sentimientos positivos y disfrutan en mayor medida las consecuencias satisfactorias de las relaciones sociales.

Riegery y Collage (2004) recogen la atribución que las familias de personas con discapacidad intelectual llevan a cabo acerca de los beneficios del humor en ellas, atribuyendo a éste la función de liberar a la persona de experiencias de estrés, servir de mecanismo de resolución de problemas y una forma de comunicación, así como un medio para fomentar estilos de pensamiento más optimistas y adaptativos. Si bien es cierto que los distintos componentes del sentido del humor pueden generar efectos diferenciales respecto al bienestar psicológico, sobre todo en personas con discapacidad intelectual, algunos de estos pueden ser beneficiosos para éstas y otros perjudiciales. Los aspectos desadaptativos del humor son, según Kuiper, Grimshaw, Leite y Kirsh (2004), los que no se centran en la propia persona, sino que se proyectan hacia los demás generando un carácter agresivo y grosero del humor. Los componentes positivos, en cambio, generan una buena adaptación de la persona con discapacidad intelectual y del desarrollo, y se asocian con una mayor autoestima, niveles de ansiedad más bajos y juicios de autoconcepto más positivos. En esta línea, Martin, Puhlik-Doris, Larsen, Gray y Weir (2003), a través de la validación de la escala de sentido del humor (HSQ), permiten determinar los aspectos negativos y positivos del mismo. En dicha herramienta se contemplan cuatro dimensiones relativas a las diferencias individuales en el uso del humor: para mejorar aspectos psicológicos propios de la persona (dimensión de auto-mejora), para mejorar las relaciones con los demás (dimensión afiliativa), para mejorar la autoestima a consecuencia de otros (humor agresivo) y para mejorar las relaciones a consecuencia de uno mismo (dimensión autodestructiva). Estos autores han obtenido evidencias acerca de cómo estas dimensiones correlacionan de forma diferente con el estado de ánimo, la ansiedad, la autoestima, 
el optimismo, el bienestar y el apoyo social. Siendo las dos primeras las más positivas para la persona.

Uno de los modelos que mejor explican el constructo "sentido del humor", por lo coherente que se ha mostrado tras años de trabajos de investigación empírica, es el presentado por García-Larrauri (2004, 2006) y denominado modelo multidimensional del sentido del humor.

Éste se compone de cuatro dimensiones: una, “creación o generación de humor", abarca la faceta más externa y evidente del sentido del humor y refiere directamente al conjunto de estrategias y habilidades propias para percibir la realidad de forma insólita y comunicarla de modo que provoque risas o sonrisas en los demás. Otra, "apreciación del humor y disfrute de la vida", vendría a ser el tomarse la vida en serio pero con toques de humor, pensando en positivo, apreciando el sentido del humor de los demás y riéndose de uno mismo o de sus situaciones. Una tercera, "afrontamiento optimista de problemas", es el uso del sentido del humor para hacer frente a los avatares, las dificultades, los contratiempos y los fracasos de la vida. Y, por último, la dimensión que hace referencia al "establecimiento de relaciones positivas”, supone la utilización del humor como una herramienta para comunicarse y relacionarse socialmente de manera más eficaz.

Diferentes investigaciones vienen demostrando la importancia del sentido del humor en la población general y su relación con el bienestar personal y con la salud. Sin embargo, son muy pocas las que se centran en poblaciones específicas como son las personas con discapacidad intelectual y del desarrollo. Por otro lado, existen evidencias claras de que el sentido del humor es una experiencia emocional presente en las personas con discapacidad intelectual y del desarrollo (Paredes, 2008).

Sin embargo, algunos de los escasos estudios existentes muestran determinados valores diferenciales entre las muestras infantiles de personas con discapacidad intelectual y del desarrollo con respecto a niños de capacidades ordinarias. Así, Bruno, Johnson y Simon (I988) mantienen que los niños con discapacidad intelectual tenían tasas más bajas de humor que los ordinarios. St. James y Tager-Flusberg (I 994) y Reddy Williams y Vaughan (2002) proponen que los niños con trastornos de espectro autista tienen menos sentido del humor que niños con síndrome de Down. Por su parte, Degabriele y Walsh (20I0) proponen que el modo de

Figura 1. Modelo multidimensional del sentido del humor de García-Larrauri (2004)

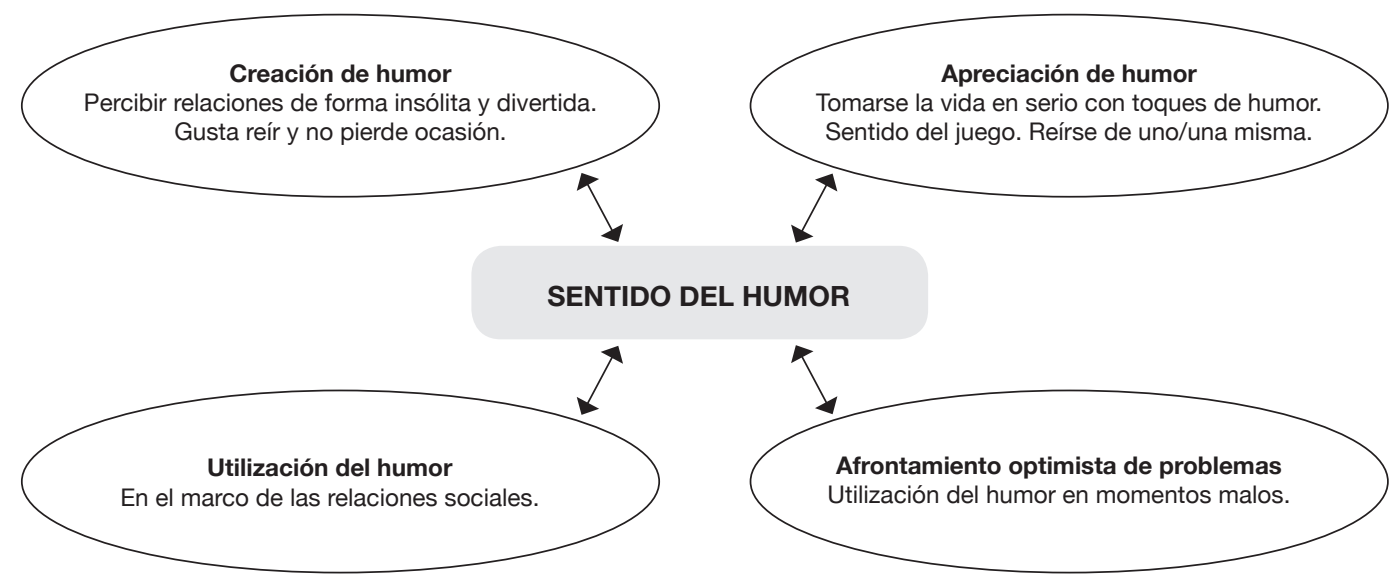


presentación del humor es importante para explicar qué encuentran divertido los niños con discapacidad intelectual.

Todos estos estudios hacen referencia a muestras de población infantil. Sobre el sentido del humor en la edad adulta de las personas con discapacidad intelectual y del desarrollo apenas hay algún estudio. Por esto cabe preguntarse si existirían también diferencias en su sentido del humor con respecto al del resto de la población y, por tanto, si el modelo explicativo al que se viene haciendo referencia es aplicable también a estas personas.

\section{Literatura de humor y discapacidad intelectual}

Uno de los aspectos más interesantes del sentido del humor es la enorme oferta de presentaciones que puede soportar. Así, por ejemplo, en las conversaciones cotidianas las personas suelen hacer comentarios humorísticos sobre la realidad más inmediata, narrando anécdotas graciosas o contando chistes. También los medios de comunicación de masas exponen creaciones humorísticas en películas, series de televisión que se basan en la comedia, en producciones de dibujos animados, etc. La expresión del humor y su consecuente recepción también puede tener una forma de representación artística en vivo por medio de la representación de obras teatrales o, simbólicamente, a través de títeres y marionetas.

Y como no podía ser de otra manera debe mencionarse el soporte gráfico e impreso en papel: viñetas en los diarios y periódicos, cómics y tebeos y, por supuesto, obras literarias. En cualquier caso, es evidente que las diferentes formas de presentación del humor exigen diferentes niveles de lenguaje y de procesamiento cognitivo por parte del oyente-lector-espectador. Así pues, las competencias en habilidades verbales, visuales, auditivas y perceptivas están involucradas, de una u otra manera, en la decodificación de cualquier caso particular de presentación humorística. Además, otro factor como es la preferencia por una forma de presentación sobre otra también juega un papel clave en la decodificación y la apreciación del humor pues implica al interés y a la motivación. Por último, decir que no todos los soportes mantienen la misma exigencia de atención y concentración en el receptor, sin que esto ofrezca más o menos mérito a la calidad humorística de la obra.

La literatura de humor posiblemente sea uno de los soportes más exigentes para el receptor del humor. Grandes literatos como Aristófanes, Plauto, Terencio, Boccacio, Cervantes, Moliere, Mark Twain, Darío Fo, Eduardo Mendoza, Augusto Monterroso, etc. han hecho pasar muchas horas de bienestar emocional a muchísimas personas con sus obras. Y el interés por ellos, más que decrecer, parece impulsarles al estrado humano de lo universal.

Es evidente que las limitaciones intelectuales de la inmensa mayoría de las personas con discapacidad intelectual y del desarrollo les impiden aprovecharse de la gracia literaria de estos y otros muchos autores. Pero ¿̇tal cuestión significa obligatoriamente tener que resignar a las personas con discapacidad intelectual y del desarrollo a no sentir una experiencia similar?

Siendo la lectura una actividad muy recomendable para el desarrollo y el mantenimiento de las funciones cognitivas, y teniendo en cuenta que a través de su práctica con respecto a la literatura de humor se pueden experimentar emociones positivas, ¿podrían las personas adultas con discapacidad intelectual y del desarrollo aprovecharse de ella para que les genere bienestar emocional y, en definitiva, calidad de vida?

Y, por último, ¿cómo podría hacerse más asequible y comprensible el soporte literario para facilitar la experiencia de la emoción humorística a las personas adultas con discapacidad intelectual y del desarrollo? 


\section{Método}

\subsection{Naturaleza y objetivos del presente trabajo}

A fin de intentar dar respuestas a las preguntas anteriormente expresadas, se planteó la realización de un estudio exploratorio que tuviera como método de análisis un enfoque predominantemente cualitativo; no despreciando con ello la cuantificación de algunos datos.

Dicho análisis se fundamenta en asignar opiniones recogidas en entrevistas estructuradas, programadas, previamente diseñadas y realizadas personalmente a cada participante en el momento previsto en el programa. Las opiniones expresadas, textuales y/o sometidas a un escalamiento numérico elemental, se clasifican y ordenan en distintos núcleos de interés y agrupamiento de criterios para facilitar su interpretación.

De manera que se plantean los siguientes objetivos:

- Analizar si el Modelo multidimensional del sentido del humor propuesto por GarcíaLarrauri (2006) es aplicable a la población del presente estudio.

- Examinar la utilidad e idoneidad para las personas adultas con discapacidad intelectual y del desarrollo de la visualización y lectura de material humorístico en soporte impreso destinado a la población general, con un nivel de lectura característico de las edades comprendidas entre los I I y I 2 años.

- Y descubrir las preferencias de los participantes en el material humorístico en soporte impreso: sea (a) sólo a través del texto escrito y sea (b) texto escrito acompañado de dibujos presentados en forma de viñetas.

\subsection{Muestra de participantes}

Dado el carácter exploratorio del estudio, se decidió utilizar una muestra de conveniencia eligiendo a los participantes entre los usuarios y usuarias de un centro de apoyo a personas adultas con discapacidad intelectual y del desarrollo.

Los criterios de selección que se utilizaron fueron los siguientes: (I) deseo expresado de participación voluntaria en la actividad, tras ser convenientemente informado de su propósito y contenido; (2) poseer un nivel medio de habilidades lectoras medidas a través del test TALE (Toro y Cervera-Rodón, I984); (3) tener un grado de discapacidad intelectual entre moderado y ligero/leve, medido con un test estandarizado de inteligencia; (4) tener cierto nivel de sentido del humor, medido a través de dos ítems, observacionales, extraídos de la escala ASPeCT-DD (Woodard, 2009); (5) poseer un bajo o nulo nivel de aquiescencia, medido a través de una lista de chequeo (Paredes, 2008); (6) tener una aptitud adecuada para la elección graduada de opciones en escalas tipo Likert, medida a través de una prueba no estandarizada (Paredes, 2008); y (7) tener un nivel de autoconocimiento personal al menos de nivel medio, medido a través de la sub-escala correspondiente de la prueba $A R C$ (Wehmeyer et al., 2006).

De manera que se realizó una propuesta inicial de participación en el programa a dieciséis personas. Esta fue rechazada por cinco personas, dos de ellas manifiestan su deseo de no participar desde el inicio y tres de ellas no llegan a leer el libro pese a que se lo llevan a casa. Aceptan participar un total de once personas. Uno de ellos primero rechaza participar y por fin acepta.

El perfil de la muestra quedó como sigue: I I participantes en total, de los cuales 4 eran mujeres y 7 hombres, cuya edad media es de 36 años (máximo 5I años y mínimo 23 años) y CI medio de 67 puntos (máximo 70 puntos y mínimo 50 puntos). Todos tenían aptitudes para escoger al menos entre tres opciones en escalas tipo Likert, poseían un bajo o muy bajo nivel de aquiescencia y demostraron al menos un nivel medio de comprensión lectora. Asimismo, existía un buen nivel medio de 
autoconocimiento y se les reconocía la presencia del sentido del humor en sus rasgos personales.

\subsection{Procedimiento}

\section{a. Variable independiente}

Se utilizaron como estímulos libros recopilatorios de chistes populares, cuyo texto fuese muy corto y su lenguaje muy sencillo. Otros criterios de selección que se aplicaron para la elección de los volúmenes fueron su fácil adquisición en el mercado, ser muy baratos y que contuvieran textos apropiados para ser entendidos por personas cuya estructura de pensamiento fuese propia de la etapa de operaciones concretas o que estuvieran en el inicio de las operaciones formales; correspondiendo aproximadamente a II-I 2 años en la población ordinaria.

Se manejaron dos tipos de libros: (a) libros exclusivamente con texto escrito ("solo texto") y (b) libros con texto escrito acompañado de dibujos ("viñetas"). En total se manejaron cuatro volúmenes de "solo texto" (cuyos títulos fueron: Los mejores chistes cortos, Chistes para todos, Chistes para niños; al borde de un ataque de risa, y Chistes para niños) y dos de "viñetas" (cuyos títulos fueron: 365 Chistes y 365 Chistes... y más). Cada participante tuvo acceso a un solo volumen de cada tipo de libro.
Para la medida del impacto de los estímulos y la comprobación del logro de los objetivos de investigación se diseñó una entrevista estructurada que contenía I 5 preguntas, organizadas en dos formularios diferenciados, A y B, que se aplicaron respectivamente al finalizar cada tipo de libro. Ambas formas contenían nueve preguntas comunes y tres exclusivas.

En la redacción de las preguntas se tuvieron en cuenta, por una parte, determinados puntos de interés tales como la valoración general del libro y la descripción de sus características por parte del lector; el supuesto efecto emocional provocado; si fue bien comprendido el texto escrito; si el llevar a cabo la actividad había generado un determinado provecho; la expresión de la preferencia por uno de los dos soportes gráficos y otros aspectos similares. Con ello se buscó la consistencia en los resultados y el control para la validez de los mismos.

Y por otra, la entrevista contenía preguntas con referencias no exclusivas a las dimensiones del modelo multidimensional del sentido del humor de García-Larrauri (2006), estas fueron las siguientes: para "apreciación del humor y disfrute de la vida" se dedicaron tres preguntas. Para "establecimiento de relaciones positivas", tres preguntas. Para "creación y generación de humor”, cinco preguntas. Y para "afrontamiento optimista de los problemas", dos preguntas.

\section{Figura 2. Ejemplos de libros "solo texto" y de libros con "viñetas"}

EJEMPLO DE LIBRO "SOLO TEXTO”

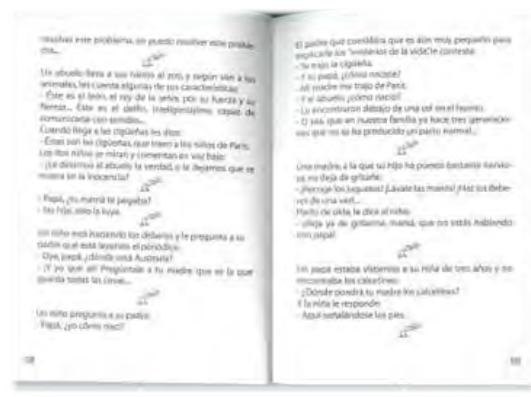

EJEMPLO DE LIBRO CON "VIÑETAS"

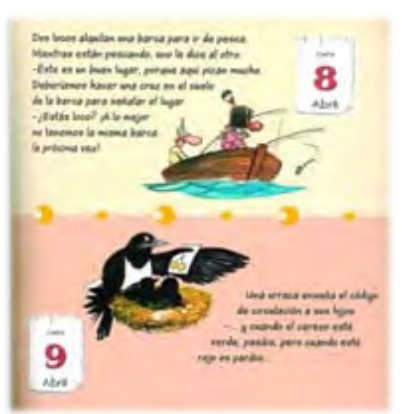


Tabla 1. Estructura de la entrevista empleada en el estudio

\begin{tabular}{|c|c|c|c|c|}
\hline Descripción de la pregunta & Punto de interés & $\begin{array}{l}\text { Principal dimensión } \\
\text { implicada }\end{array}$ & $\begin{array}{l}\text { Tipo de } \\
\text { pregunta }\end{array}$ & $\begin{array}{c}\text { Presencia en } \\
\text { formulario }\end{array}$ \\
\hline \multirow{3}{*}{$\begin{array}{l}\text { ¿Cómo te ha parecido el libro? } \\
\text { ¿Te ha gustado? }\end{array}$} & $\begin{array}{l}\text { Valoración general del } \\
\text { libro } \\
\text { Validez }\end{array}$ & Ninguna & \multirow{3}{*}{ Abierta } & \multirow{3}{*}{$\begin{array}{l}\text { Forma } \\
\text { A y B }\end{array}$} \\
\hline & \begin{tabular}{|l|} 
Descripción \\
características del libro \\
\end{tabular} & Ninguna & & \\
\hline & $\begin{array}{l}\text { Efecto emocional } \\
\text { provocado }\end{array}$ & $\begin{array}{l}\text { Apreciación del humor y } \\
\text { disfrute de la vida }\end{array}$ & & \\
\hline $\begin{array}{l}\text { ¿Has comprendido bien los } \\
\text { chistes del libro? }\end{array}$ & $\begin{array}{l}\text { Comprensión lectora } \\
\text { Valoración del programa }\end{array}$ & Ninguna & $\begin{array}{l}\text { Likert con } 3 \\
\text { opciones de } \\
\text { elección }\end{array}$ & $\begin{array}{l}\text { Forma } \\
\text { A y B }\end{array}$ \\
\hline $\begin{array}{l}\text { ¿Has contado algún chiste del } \\
\text { libro?, por ejemplo a...Amigo- } \\
\text { Familiar-Monito }\end{array}$ & Relación social & $\begin{array}{l}\text { Establecimiento de } \\
\text { relaciones positivas } \\
\text { Creación y generación de } \\
\text { humor }\end{array}$ & $\begin{array}{c}\text { SI/NO } \\
\text { (para cada } \\
\text { posibilidad) }\end{array}$ & $\begin{array}{l}\text { Forma } \\
\text { A y B }\end{array}$ \\
\hline $\begin{array}{l}\text { ¿Has dicho a alguien que } \\
\text { estabas leyendo este libro de } \\
\text { chistes? a... Amigo-Familiar - } \\
\text { Monitor. }\end{array}$ & Relación social & $\begin{array}{l}\text { Establecimiento de } \\
\text { relaciones positivas }\end{array}$ & $\begin{array}{c}\text { SI/NO } \\
\text { (para cada } \\
\text { posibilidad) }\end{array}$ & $\begin{array}{l}\text { Forma } \\
\text { A y B }\end{array}$ \\
\hline $\begin{array}{l}\text { ¿Te sabías ya algún chiste de los } \\
\text { que vienen en el libro? }\end{array}$ & $\begin{array}{l}\text { Cognición, Memoria } \\
\text { Valoración del programa }\end{array}$ & $\begin{array}{l}\text { Creación o generación de } \\
\text { humor }\end{array}$ & $\begin{array}{c}\mathrm{SI} / \mathrm{NO} y \\
\text { abierta para la } \\
\text { afirmativa }\end{array}$ & $\begin{array}{l}\text { Forma } \\
\text { A y B }\end{array}$ \\
\hline $\begin{array}{l}\text { ¿Te sabes algún chiste que no } \\
\text { venga en el libro? }\end{array}$ & $\begin{array}{l}\text { Cognición, Memoria } \\
\text { Valoración del programa }\end{array}$ & $\begin{array}{l}\text { Creación o generación de } \\
\text { humor }\end{array}$ & $\begin{array}{l}\mathrm{SI} / \mathrm{NO} y \\
\text { abierta para la } \\
\text { afirmativa }\end{array}$ & $\begin{array}{l}\text { Forma } \\
\text { A y B }\end{array}$ \\
\hline $\begin{array}{l}\text { ¿Cómo te lo has pasado leyendo } \\
\text { el libro? }\end{array}$ & $\begin{array}{l}\text { Efecto emocional } \\
\text { provocado }\end{array}$ & $\begin{array}{l}\text { Apreciación del humor y } \\
\text { disfrute de la vida }\end{array}$ & Abierta & $\begin{array}{l}\text { Forma } \\
\text { A y B }\end{array}$ \\
\hline $\begin{array}{l}\text { ¿Crees que eres una persona } \\
\text { que sabes contar chistes? }\end{array}$ & Autoconocimiento & $\begin{array}{l}\text { Creación o generación de } \\
\text { humor } \\
\text { Establecimiento de } \\
\text { relaciones positivas }\end{array}$ & $\begin{array}{l}\text { Likert } 3 \\
\text { opciones y } \\
\text { abierta para } 2 \\
\text { de ellas. }\end{array}$ & $\begin{array}{l}\text { Forma B } \\
\text { Viñetas }\end{array}$ \\
\hline $\begin{array}{l}\text { ¿Le dirás a alguien que lea este } \\
\text { libro de chistes? }\end{array}$ & $\begin{array}{l}\text { Interés suscitado por la } \\
\text { actividad } \\
\text { Valoración del programa } \\
\end{array}$ & Ninguna. & $\begin{array}{c}\mathrm{SI} / \mathrm{NO} \text { y } \\
\text { abierta para la } \\
\text { afirmativa }\end{array}$ & $\begin{array}{l}\text { Forma } \\
\text { A y B }\end{array}$ \\
\hline ¿Eres una persona graciosa? & Autoconocimiento & $\begin{array}{l}\text { Creación o generación de } \\
\text { humor }\end{array}$ & $\begin{array}{l}\text { Likert con } 3 \\
\text { opciones de } \\
\text { elección }\end{array}$ & $\begin{array}{l}\text { Forma A } \\
\text { Solo texto }\end{array}$ \\
\hline $\begin{array}{l}\text { ¿Crees que eres una persona } \\
\text { que tienes buen sentido del } \\
\text { humor? }\end{array}$ & Autoconocimiento & $\begin{array}{l}\text { Apreciación del humor y } \\
\text { disfrute de la vida } \\
\text { Afrontamiento optimista } \\
\text { de problemas }\end{array}$ & $\begin{array}{l}\text { Likert con } 3 \\
\text { opciones de } \\
\text { elección }\end{array}$ & $\begin{array}{l}\text { Forma A } \\
\text { Solo texto }\end{array}$ \\
\hline $\begin{array}{l}\text { ¿Eres una persona que sabes } \\
\text { inventarte cosas divertidas? }\end{array}$ & Autoconocimiento & $\begin{array}{l}\text { Afrontamiento optimista } \\
\text { de los problemas }\end{array}$ & $\begin{array}{c}\mathrm{SI} / \mathrm{NO} y \\
\text { abierta para la } \\
\text { afirmativa }\end{array}$ & $\begin{array}{l}\text { Forma B } \\
\text { Viñetas }\end{array}$ \\
\hline $\begin{array}{l}\text { ¿Para qué crees que te ha } \\
\text { servido haber leído este libro de } \\
\text { chistes? }\end{array}$ & Utilidad de la actividad & Todas las dimensiones & Abierta & $\begin{array}{l}\text { Forma } \\
\text { A y B }\end{array}$ \\
\hline $\begin{array}{l}\text { ¿Quieres que te preste otro libro } \\
\text { parecido? }\end{array}$ & $\begin{array}{l}\text { Interés suscitado por la } \\
\text { actividad } \\
\text { Valoración del programa } \\
\end{array}$ & Ninguna & $\begin{array}{l}\text { Dicotómica SI/ } \\
\text { NO }\end{array}$ & $\begin{array}{l}\text { Forma A } \\
\text { Solo texto }\end{array}$ \\
\hline $\begin{array}{l}\text { ¿Qué libro de chistes te ha } \\
\text { gustado más: éste con dibujos o } \\
\text { el otro sin dibujos? ¿Por qué? }\end{array}$ & $\begin{array}{l}\text { Preferencia por soporte } \\
\text { para lectura }\end{array}$ & Ninguna & $\begin{array}{l}\text { Dicotómica } \\
\text { UNO/OTRO }\end{array}$ & $\begin{array}{l}\text { Forma B } \\
\text { Viñetas }\end{array}$ \\
\hline
\end{tabular}


La entrevista contempló una estructura con varios tipos de preguntas: abiertas, dicotómicas, con una escala de elección graduada en tres opciones y semi-abiertas con respuesta secundaria.

\section{c. Programa operativo}

Tras una primera oferta verbal del responsable del programa, el cual era sobradamente conocido por los posibles participantes, se ofertaba la lectura de un libro anunciando que era divertido pues contenía chistes. De aceptar se daba al participante un libro "sólo texto". A continuación se supervisaba la realización de la actividad y se hacía un seguimiento de la misma. Si pasada una semana el sujeto no mostraba interés suficiente, por ejemplo decía no haber empezado a leer el libro, se le excluía del programa.

Si sucedía lo contrario, el sujeto había comenzado a leer el libro y mostraba interés en él, se le reforzaba socialmente para que continuase. Una vez que anunciaba la finalización del libro se le aplicaba al sujeto la entrevista en su forma A, siempre de manera individualizada, personalmente por el responsable del programa y en un espacio adecuado; y se le ofertaba otro libro anunciando que esta vez contenía dibujos; de rechazar el nuevo libro, caso que no ocurrió, se le excluía del programa. Al finalizar su lectura se le aplicaba la entrevista en su forma B; en similares condiciones que la anterior.

Figura 4. Proceso del programa operativo

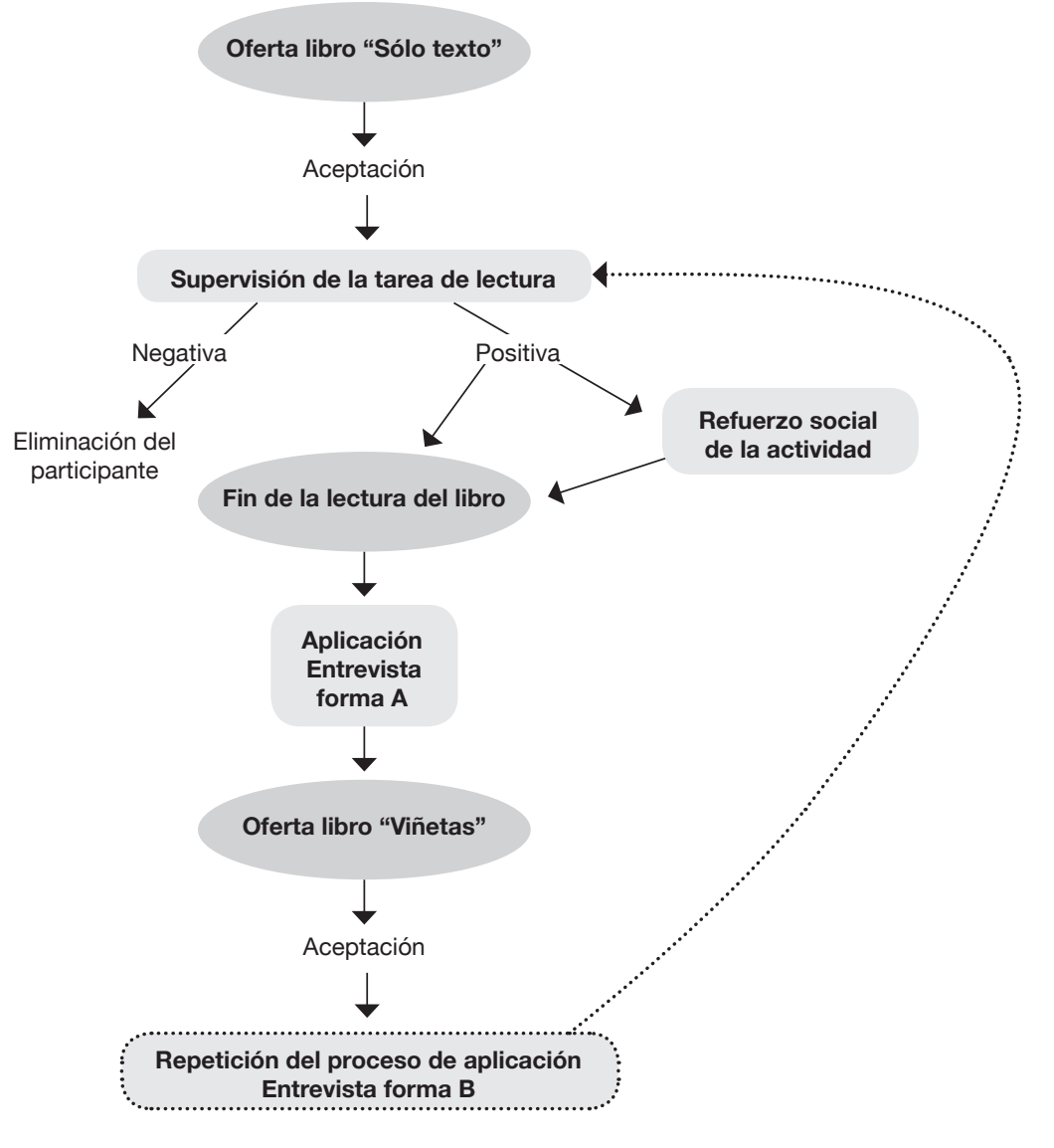


Los libros "sólo texto" estuvieron una media de I4 días en manos de los lectores, con un máximo de 50 días y un mínimo de 5 . Por su parte, los libros “viñetas" estuvieron en manos de los lectores una media de ${ }_{5}$ días, con un máximo de 45 y un mínimo de 3 días.

\section{Resultados}

Las respuestas registradas en los formularios de la entrevista fueron analizadas por los investigadores y agrupadas en los epígrafes siguientes:

- Valoración general de los soportes gráficos.

- Generación de bienestar y efectos emocionales provocados.

- Detección de la presencia de las distintas dimensiones del modelo multidimensional del sentido del humor de García-Larrauri (2006).

- $\quad$ Utilidad percibida de la actividad y valoración del programa por parte de los participantes.

- $\quad$ Preferencia por el tipo de soporte gráfico.

Se obtuvieron los siguientes resultados:

- Valoración general de los soportes gráficos: Las características de los libros han sido valoradas por los participantes positivamente, en la gran mayoría de los casos. Encontrándose similares respuestas en los dos tipos de libro presentados. Algunos ejemplos de comentarios expresados son: "estuvo bien”, “me ha gustado el libro”, "es gracioso“, "es bonito", "es un libro divertido", "algunos chistes eran poco graciosos”, entre otros. No hubo ninguna respuesta totalmente negativa.

- Generación de bienestar y efectos emocionales provocados: Los participantes expresaron que la actividad les generó y provocó emociones positivas. Dándose similares respuestas en ambos tipos de libros. Algunos ejemplos de comentarios expresados son: "me he divertido", "me he reído", "me lo pasé regular, algunos chistes no eran buenos", "había algunos chistes raros", "me lo he pasado estupendamente leyendo el libro", etcétera.

- Detección de la presencia de las distintas dimensiones del modelo multidimensional del sentido del humor: Las personas con discapacidad intelectual y del desarrollo participantes, reconocieron como propia la experiencia emocional humorística generada por la lectura de los libros de chistes populares que se les presentaron, sea en forma de texto exclusivo, sea en forma de texto con dibujos; por tanto, aprecian el humor y lo usan para disfrutar la vida.

- Más de dos tercios de los participantes se autoestimaron como personas con buen sentido del humor. La mayoría consideró ser una persona “chistosa”. Más del 80\% de los participantes se consideró una persona "algo graciosa" o "muy graciosa", dentro de una escala graduada de tres opciones progresivas de menos a más. Declaran que saben sacarle chispa a la vida, que a veces se inventan cosas graciosas y que desean hacer reír a personas con las que tienen una estrecha relación afectiva, tales como familiares y amigos. Por tanto una gran mayoría de los sujetos participantes consideran que crean humor, pero no supieron detallar si esto les servía para enfrentarse a los problemas cotidianos de manera positiva.

El programa parece haber generado relaciones sociales en los participantes en forma de relaciones positivas. Si bien hay algunas diferencias en cuanto al tipo de libro. Así, los libros "solo texto" provocaron más conductas de relación social, sobre todo para con los amigos a los que fueron contados algunos chistes, según los entrevistados, y familiares, siendo estos los que recibieron más información sobre la actividad realizada. Los profesionales de 
apoyo quedaron al margen de la actividad, no recibieron información de la realización de la misma ni fueron objeto de recepción de chistes o anécdotas graciosas.

Por otra parte, casi la totalidad de los participantes dijeron que recomendarían ambos libros a alguien pero que éste sería un compañero, no un familiar o un profesional de apoyo.

- $\quad$ Utilidad percibida de la actividad y valoración del programa por parte de los participantes: A tenor de las respuestas emitidas el programa parece haber sido idóneo y ajustado a las características de los participantes. Los textos en forma de chistes populares han sido asequibles a la capacidad lectora de los participantes. Todos dijeron que habían comprendido, al menos, la mayoría de los chistes de ambos tipos de libro.

- Y reconocieron que la actividad les resultó de utilidad. Algunas respuestas significativas fueron: "me he sentido mejor", "para aprender a leer mejor”, "para pensar”, "para aprender a contar chistes", "para reírme mucho", "para entretenerme”, "para estar tranquilo y no pensar en las cosas que me ponen nervioso", etcétera.

- Preferencia por el tipo de soporte gráfico: Por último, en cuanto al tipo de soporte el libro tipo "viñetas" parece tener más peso como elección preferida con un desequilibrio a su favor del $65 \%$ de las respuestas, frente a $35 \%$ de las respuestas que afirmaban la preferencia por el libro tipo "sólo texto".

\section{Discusión}

En el presente estudio se corrobora, en primer lugar, la evidencia de que las personas con discapacidad intelectual y del desarrollo tienen experiencias emocionales de sentido del humor. Y que esta competencia emocional puede y debe ser aprovechada para aumentar sus niveles de calidad de vida en tanto que genera bienestar emocional.

En segundo lugar, cabe mencionar que una buena forma de promover su sentido del humor es utilizando, siempre que se ajuste a sus aptitudes intelectuales y lectoras, la literatura de humor popular, adaptada en forma de textos sencillos y/o acompañados de dibujos.

Los resultados parecen arrojar bastante consistencia interna a la idoneidad del programa, en tanto que es significativo, por ejemplo, que tras la lectura del primer libro ("sólo texto"), que a priori puede parecer más arduo que el segundo ("viñetas”), todos los participantes aceptaron continuar con la actividad. O que el material utilizado haya sido considerado válido en términos de comprensibilidad.

Algunos participantes manifestaron que conocían algún chiste, sobre todo de los libros tipo "sólo texto", pero esto más que un hándicap puede ser considerado como un valor positivo, pues si bien encontrar en el texto chistes no conocidos puede generar una idea de novedad que mantenga el interés por la actividad, reconocer algunos según se lee puede ser también reforzante.

Además, los estímulos, sean del tipo que fuesen, se consideraron adecuados para generar experiencias emocionales humorísticas. Esta valoración positiva lleva a la opinión de que los resultados ofrecen consistencia interna.

Por otra parte, casi la totalidad de los participantes dijeron que recomendarían ambos libros a alguien, pero siempre a un compañero, no a un familiar o a un profesional de apoyo. Las respuestas, en cualquier caso, en forma de intención provocada por el entrevistador, aseguran consistencia a los resultados, pues la actividad fue creída no sólo gustosa para sí mismo sino también como adecuada para sus iguales. 
Al ser un estudio exploratorio, cualitativo y con una muestra de conveniencia muy reducida, evidentemente deben reconocerse grandes limitaciones para poder obtener resultados concluyentes. Además, la falta de estudios con los que establecer referencias añade más dificultad al asunto. Pero en cualquier caso, desde la consideración de esta advertencia, puede decirse que todas las dimensiones del modelo multidimensional del sentido del humor presentado por García-Larrauri (2004, 2006) parecen estar presentes también en las personas con discapacidad intelectual y del desarrollo; este dato apoya las evidencias encontradas por Paredes (2008) acerca de que el sentido del humor es una experiencia emocional presente en las personas con discapacidad intelectual y del desarrollo. Sin embargo, no todas estas dimensiones aparecen con la misma claridad, tienen la misma intensidad o poseen la misma utilidad.

Está claro que las personas con discapacidad intelectual y del desarrollo generan y aprecian el sentido del humor y que éste les sirve para disfrutar de la vida. También que a través del mismo mantienen relaciones sociales positivas, con los beneficios que ello conlleva, según lo propuesto por Moran y Hughes (2006). Pero ¿les es útil para saber afrontar las dificultades de la vida con optimismo? Con los datos disponibles esta duda no ha podido ser resulta en el presente estudio.

Por último, se ha encontrado que los participantes muestran más preferencia por el formato "viñetas" frente al formato "sólo texto". Sin embargo, el resultado tiene muchas limitaciones en su interpretación, por lo que debe ser estimado como poco consistente en razón de las dudas que genera. Este dato es congruente con lo propuesto por Degabriele y Walsh (20I0) acerca de la importancia del modo de presentación del humor para explicar qué encuentran más divertido las personas con discapacidad intelectual.

En primer lugar, siendo la fuente principal de datos la respuesta a una única pregunta (¿Qué libro de chistes te ha gustado más: éste con dibujos o el otro sin dibujos. Y por qué?), y realizada al final de la segunda entrevista ¿pudiera haber interferido la fatiga psicológica en algunos o en muchos de los entrevistados y que ella condicionase a la baja la intensidad argumental de la respuesta? De hecho, aparte de la mera elección entre una u otra opción, la aportación de razones resultó excesivamente escueta en todos los participantes. Lo que impidió un tratamiento más pormenorizado de las respuestas y la imposibilidad de obtención de conclusiones más sólidas.

En segundo lugar, ¿podría haber influido y en qué medida el estilo del estímulo gráfico presentado? Frente a un estilo "solo texto" que siempre es igual en todos los libros (variando evidentemente el tipo y tamaño de la letra y el volumen del libro en sí mismo) el estilo del formato "viñetas" puede variar enormemente en su composición, expresión o colorido. De manera que solo se puede concluir que los participantes optaron, frente al formato "solo texto", por el formato "viñetas", referido éste al libro estímulo concreto que le fue presentado y no al concepto genérico de preferir siempre textos unidos a dibujos ante otros sin ellos.

Por último, alguna otra variable no controlada (por la dificultad que entraña) pudiera sesgar también el resultado, como es la valoración subjetiva de la calidad de los chistes, expresada en una sola opinión a favor del formato "solo texto" como "elijo este libro por que los chistes son mejores".

Pese a todo, el mero dato descriptivo que se expone en los resultados ya es algo más que la ausencia de datos. Las dudas y las carencias metodológicas expuestas deben prevenir errores y orientar la estrategia en futuras investigaciones.

Frente a todo lo dicho, se debe tener en cuenta que la validez de contenido, buscada en una estructura de entrevista determinada y con determinados mecanismos de control de la aquiescencia o de la aptitud para las escalas Likert, puede no estar reflejada al completo en los resultados. Por ejemplo, cabe la duda 
de ¿hasta qué punto son sinceras todas las respuestas que ofrecen los participantes? Nada hace sospechar que no lo sean pero tampoco hay certeza de lo contrario.

En cualquier caso, esta investigación, aun con sus muchas limitaciones, muestra que hay indicios cada vez más sólidos de que el humor puede ser utilizado para mejorar la calidad de vida de las personas con discapacidad intelectual y del desarrollo, tanto en aspectos psicológicos y emocionales como la mejora de la fluidez del pensamiento, una mejora en el afrontamiento de los eventos vitales adversos o una visión más creativa de cara a la solución de problemas cotidianos (Avia, I995, I998; Vecina, 2006), así como en los aspectos más relacionados con la salud física donde genera una mejora a nivel cardiovascular, endocrino, respiratorio y neuronal, como refiere Martin (2004).

Y aunque se necesita aumentar mucho el conocimiento que se tiene sobre el tema, la aplicación de programas como el aquí presentado parece tener utilidad para el propósito implícito perseguido: aumentar el bienestar emocional, lograr habilidades para mantenerlo y conseguir calidad de vida.

Pese a las evidencias expuestas o a las dudas planteadas, el resultado que aparece más claramente diáfano es que el programa ha generado diversión, ha sido fácil de aplicar y resultó muy viable en cuanto a recursos.

Por último, es necesario mencionar la necesidad de seguir ampliando los conocimientos con respecto al sentido del humor y las personas con discapacidad intelectual y del desarrollo adultas. Para saber, por ejemplo, cuáles serían los diseños de aprendizaje y entrenamiento más apropiados para que sepan apreciar mejor lo humorístico de la vida, para que logren generar mejores relaciones sociales positivas utilizando el gracejo o para que afronten los problemas cotidianos de sus vidas de una manera optimista. 
Avia, M. D. (1995): "Personas felices: las emociones positivas”. En: Avia, M. D. y Sánchez Bernardos, M. L.: Personalidad: aspectos cognitivos y sociales, Madrid: Pirámide: 463-478.

Avia, M. D. y Vázquez, C. (I998): Optimismo inteligente, Madrid: Alianza.

Bruno, R. M.; Johnson, J. M. y Simon, J. (I988): "Perception of humor by learning disabled, mildly retarded, and nondisabled students", Learning Disabilities Focus, 3(2): I I4-I 23.

Carbelo, B. y Jáuregui, E. (2006): “Emociones positivas: humor positivo", Papeles del Psicólogo, 27(I): I8-30.

Degabriele, J. y Walsh, I.P. (2010): “Humour appreciation and comprehension in children with intellectual disability", Journal of Intellectual Disability Research, 54(6): 525-537.

García-Larrauri, B. (2006): Programa para mejorar el sentido del humor, Madrid: Pirámide.

García-Larrauri, B. et al. (2004): "Sentido del humor: delimitación conceptual, evaluación y propuestas de intervención". En: Ruiz, M. I. et al. (eds): Aportaciones psicológicas y desarrollo difícil, Badajoz: Psicoex: 387-430.

Kuiper, N. et al. (2004): "Humor is not always the best medicine: Specific components of sense of humor and psychological well-being”, Humor - International Journal of Humor Research, I $7(\mathrm{I} / 2):$ I 35 -I 68 .

Martin. R. A. (2004): "Sense of humor and physical health: Theoretical issues, recent findings, and future directions", Humor International Journal of Humor Research, I7 (I/2): I-I9.

Martin, R. A. et al. (2003): "Individual differences in uses of humor and their relation to psychological well-being: Development of the Humor Styles Questionnaire”, Journal of Research in Personality, 37: 48-75.
Moran, C. C. \& Hughes, L. P. (2006): "Coping with stress: social work students and humour", Social Work Education, 25(5): 50I-5I7.

Paredes, D. (2008a): Lista de chequeo / entrevista para detectar la aquiescencia. (Inédito).

Paredes, D. (2008b): Lista de chequeo/entrevista para comprobar la aptitud de elección en escalas Likert. (Inédito).

Paredes, D. (2008c): "La experiencia del humor en las personas con discapacidad intelectual", Electronic Journal of Research in Educational Psychology, 6(I): 20I-2I 8.

Reddy, V.; Williams, E. y Vaughan, A. (2002): "Sharing humour and laughter in autism and Down's syndrome", British Journal of Psychology, 93(2): 219-24I.

Rieger, A. \& Collage, U. (2004): "Explorations of the Functions of Humor and Other Types of Fun Among Families of Children With Disabilities", Research \& Practice for Persons with Severe Disabilities, 29(3): 194-209.

St. James, P. J. y Tager-Flusberg, H. (I994): “A observational study of humor in autism and Down syndrome", Journal of Autism and Developmental Disorders, 24(5): 603-617.

Toro, J. y Cervera-Rodón, M. (I984): TALE. Test de aprendizaje de la lectoescritura, Barcelona: Visor.

Vecina, M. L. (2006): "Emociones positivas", Papeles del Psicólogo, 27(I): 9-I7.

Wehmeyer, M. et al. (2006): Escala ARC. Adaptación española, Madrid: CEPE.

Woodard, C. (2009): "Psychometric properties of ASPeCT-DD: measuring positive traits in persons with developmental disabilities", Journal of Applied Research in Intellectual Disability, 22(5): 433-444. 